\title{
ASSET ALLOCATION AND ANNUITY-PURCHASE STRATEGIES TO MINIMIZE THE PROBABILITY OF FINANCIAL RUIN
}

\author{
Moshe A. Milevsky \\ Schulich School of Business, York University, \\ Toronto, Ontario, Canada
}

KRISTEN S. MOORE

Department of Mathematics, University of Michigan, Ann Arbor, Michigan, USA

VIRGINIA R. YOUNG

Department of Mathematics, University of Michigan, Ann Arbor, Michigan, USA

\begin{abstract}
In this paper, we derive the optimal investment and annuitization strategies for a retiree whose objective is to minimize the probability of lifetime ruin, namely the probability that a fixed consumption strategy will lead to zero wealth while the individual is still alive. Recent papers in the insurance economics literature have examined utilitymaximizing annuitization strategies. Others in the probability, finance, and risk management literature have derived shortfall-minimizing investment and hedging strategies given a limited amount of initial capital. This paper brings the two strands of research together. Our model pre-supposes a retiree who does not currently have sufficient wealth to purchase a life annuity that will yield her exogenously desired fixed consumption level. She seeks the asset allocation and annuitization strategy that will minimize the probability of lifetime ruin. We demonstrate that because of the binary nature of the investor's goal, she will not annuitize any of her wealth until she can fully cover her desired consumption with a life annuity. We derive a variational inequality that governs the ruin probability and the optimal strategies, and we demonstrate that the problem can be recast as a related optimal stopping problem which yields a free-boundary problem that is more tractable. We numerically calculate the ruin probability and optimal strategies and examine how they change as we vary the mortality assumption and parameters of the financial model. Moreover, for the special case of exponential future lifetime, we solve the (dual) problem explicitly. As a byproduct of our calculations, we are able to quantify the reduction in lifetime ruin probability that comes from being able to manage the investment portfolio dynamically and purchase annuities.
\end{abstract}

KEY WorDS: insurance, life annuities, retirement, optimal investment, shortfall risk, stochastic optimal control, barrier policies, dynamic programming, free-boundary problem, variational inequality

We thank an anonymous referee for many helpful comments. We thank Erhan Bayraktar, David Promislow, and Thomas Salisbury for fruitful discussions of this work, and we thank the participants of the 2004 IFID Conference on Risk and Mortality for their feedback.

Manuscript received June 2004; final revision received March 2005.

Address correspondence to Kristen Moore, Department of Mathematics, University of Michigan, Ann Arbor, Michigan, USA; e-mail: ksmoore@umich.edu. 


\section{INTRODUCTION AND MOTIVATION}

More individuals are responsible now than in recent decades for managing their retirement portfolios through defined contribution plans, such as 401(k)s and 403(b)s, in lieu of defined benefit pension plans. Indeed, in 1998, 62.7\% of individuals who participated in a retirement plan had a defined contribution plan as their primary plan, much higher than the 49.8\% found in 1993 (Copeland 2002). In a recent issue of The Actuary (Parikh 2003), Jeff Mohrenweiser states that "an [American Council of Life Insurers] report found that seventy-one percent of the women and sixty percent of the men surveyed are concerned that it will be difficult to make their retirement savings last a lifetime." This concern is justified; VanDerhei and Copeland (2003) report that American retirees will have at least $\$ 45$ billion less in retirement income in 2030 than what they will need to cover their expenses. This shortfall highlights the need for individuals to receive good advice about managing their wealth.

Global pension reform and the trend toward privatization have focused much academic and practitioner attention on the market for voluntary life annuities, as an alternative to defined benefit pensions. A fixed-payout life annuity is a financial instrument that pays a fixed amount periodically (e.g., monthly or annually) throughout the life of the recipient; the payments are contingent on the recipient's survival. Since they provide guaranteed, periodic income, life annuities are instrumental in helping individuals sustain a given level of consumption. Recent proposed legislation giving tax incentives for individuals who purchase these instruments testifies to their potential effectiveness in preventing poverty in retirement (Cummins 2004). While life annuities themselves are hundreds of years old - see Poterba (1997) for a brief history - it is only recently that they have attracted the attention of noted financial and insurance economists, such as Feldstein and Ranguelova (2001), as an alternative to Social Security.

Though life annuities do provide income security in retirement, very few retirees choose a life annuity over a lump sum. According to a recent survey, $86 \%$ of retirees said that guaranteed lifetime income is "very important," and $87 \%$ of retirees said that they would like to receive their pension as a series of regular payments for life (Society of Actuaries 2004); however, very few people actually elect a life annuity. Indeed, in a recent comprehensive Health and Retirement Survey, only $1.57 \%$ of the respondents reported annuity income; similarly, only $8.0 \%$ of respondents with a defined contribution pension plan selected an annuity payout.

In a well-cited paper from the public economics literature, Yaari (1965) proved that in the absence of bequest motives - and in a deterministic financial economy-consumers will annuitize all of their liquid wealth. Richard (1975) generalized this result to a stochastic environment, and a recent paper by Davidoff, Brown, and Diamond (2003) demonstrates the robustness of the Yaari (1965) result. In practice, there are market imperfections, and frictions preclude full annuitization. Similarly, Brugiavini (1993), Kapur and Orszag (1999), Brown (2001), and Milevsky and Young (2003) provide theoretical and empirical guidance on the optimal time to annuitize under various market structures.

The common theme of the above-mentioned papers is the presumption of a rational utility-maximizing economic agent with rigid inter-temporal preferences and prespecified relative risk aversion. While this von-Neumann-Morgenstern framework is the basis of most of microeconomic foundations, it is notably difficult to apply as a tool for normative advice.

Recently, though, a variety of papers in the risk and portfolio management literature have revitalized the Roy (1952) Safety-First rule and applied the concept to 
probability maximization of achieving certain investment goals. For example, Browne $(1995,1999 a, b, c)$ derived the optimal dynamic strategy for a portfolio manager who is interested in minimizing the probability of shortfall. Indeed, there is something intuitively appealing about minimizing the probability of shortfall that lends itself to asset allocation advice. In fact, in the United States, the Nobel laureate William Sharpe has founded a financial services advisory firm that is largely based on using probabilities to provide investment advice.

Therefore, motivated by the desire to apply probability optimization to problems faced by retirees, we find the optimal annuity-purchasing strategy for an individual who seeks to minimize the probability that she outlives her wealth, also called the probability of lifetime ruin. In other words, we assume the retiree will maintain a pre-specified (exogenous) consumption level, and we determine the optimal investment strategy, as well as the optimal time to annuitize, in order to minimize the probability that wealth will reach zero while the individual is still alive.

Milevsky and Robinson (2000) introduced the probability of lifetime ruin as a riskmetric for retirees, albeit in a static environment. As an extension of that work, Young (2004) determined the optimal dynamic investment policy for an individual who consumes at a specific rate, who invests in a complete financial market, and who does not buy annuities. By contrast, we allow the individual to buy annuities, as well as to invest in a financial market. The irreversibility of annuity purchases and their illiquidity creates a complex optimization environment, which renders many classical results inoperable. Of course, these same challenges are what make the problem mathematically interesting.

Our paper is organized as follows. In Section 2, we introduce the concept of selfannuitization and provide some general statements about the probability of lifetime ruin under such a strategy. We, then, present our formal optimization model and use optimal stochastic control to derive a variational inequality that governs the ruin probability and optimal strategies. We show that the annuitization strategy is a barrier strategy defined by the barrier at which the marginal ruin probability with respect to annuity income and the (adjusted) marginal ruin probability with respect to wealth are equal. This type of result - namely, taking no action until the marginal benefit is at least equal to the marginal cost - is seen often in the economics literature. The annuity-purchasing problem is qualitatively similar to the problem of optimal consumption and investment in the presence of proportional transaction costs. The difference between the two problems is that for us, once the individual's wealth reaches the barrier, then she annuitizes all her wealth, and the "game" is over, as we show in Section 3. Friedman and Shen (2002) applied similar stochastic control methods to problems in retirement planning and insurance.

In Section 3, we reduce the dimension of the variational inequality obtained in Section 2. In Section 2, the probability of lifetime ruin is given as a function of the current time, the wealth $w$ at that time, and the annuity income $A$ at that time. If $c$ denotes the (fixed) desired consumption rate, then it turns out the probability of lifetime ruin is a function of $z=w /(c-A)$ and time, so we can reduce the dimension of the problem by 1. We, then, study properties of the optimal investment and annuity-purchasing policies. We show that if wealth exceeds the actuarial present value of the investor's lifetime shortfall in consumption, then she will purchase a lump-sum annuity to guarantee her desired consumption rate so that she will never ruin. Conversely, if wealth is less than the actuarial present value of the shortfall in consumption, then the individual will buy no annuity at that time but wait until wealth is great enough, a rather surprising bang-bang result that is inherited from the nature of the investor's goal and stands in contrast to the 
instantaneous control policy that would apply if the objective were to maximize expected utility of lifetime consumption and bequest (Milevsky and Young 2003).

In Section 4, we use duality techniques to transform the nonlinear partial differential equation for the probability of lifetime ruin (with known boundary conditions) to a linear free-boundary problem. In Section 5, we solve the free-boundary problem for a special case and contrast our results with those in Section 2.1, where no annuities or risky assets were available to the individual. In this way, we quantify the benefits of dynamic portfolio management, in which the portfolio includes life annuities and a risky asset. In Section 6, we use the connection between free-boundary problems and variational inequalities for optimal stopping problems in order to compute ruin probabilities and optimal strategies for more general cases than that considered in Section 5. Section 7 concludes the paper.

\section{PROBABILITY OF LIFETIME RUIN}

In this section, we formulate our models for the probability of lifetime ruin - first in the case of deterministic returns, then in the case of stochastic returns.

\subsection{Self-Annuitization with Deterministic Returns}

In this section, we consider a simple model in which an individual can invest only in a riskless asset earning rate $r$. We assume that she begins with wealth 1 and selfannuitizes; that is, she consumes a level amount $c$ per year until she dies or runs out of money, whichever comes first. We compute the time of ruin, and under the assumption of exponential future lifetime, we compute the probability of lifetime ruin. In Section 5.2, we contrast these results with those for an investor who can trade dynamically between riskless and risky assets and who can purchase annuities instead of self-annuitizing.

We start with a future lifetime random variable $\tau_{d}$ that is exponentially distributed, for which the probability of survival is given by

$$
\operatorname{Pr}\left[\tau_{d}>t\right]=e^{-\lambda t}
$$

in which $\lambda$ is the instantaneous hazard rate (or force of mortality). The greater the hazard rate $\lambda$, the lower the probability of survival to any given age $t$.

In this paper, we refer to prices of life annuities. Formally, the price (or present value) of a payout annuity (for life, with no guarantee period) that pays $\$ 1$ per year continuously is computed via

$$
\int_{0}^{\infty} e^{-r t} \operatorname{Pr}\left[\tau_{d}>t\right] d t .
$$

It is effectively equal to the present value of $\$ 1$ per year discounted by the riskless rate and the probability of survival. The greater the interest rate, the lower the present value of the life annuity. For exponential mortality with hazard rate $\lambda$, the annuity price equals

$$
\int_{0}^{\infty} e^{-r t} e^{-\lambda t} d t=\frac{1}{r+\lambda}
$$

Note that the hazard rate acts as a discount factor in equation (2.3). Actuaries often say when computing such an expression that they are "discounting for interest and mortality."

Thus, for example, if the hazard rate is $\lambda=0.05$ (which means that future life expectancy is 20 years) and the interest rate in the (annuity) market is $r=0.07$, the price of $\$ 1$ per year for life is $1 / 0.12=8.33$ dollars. Stated differently, $\$ 1$ of initial premium will yield a fixed annuity payout of $\lambda+r=0.12$ dollars per year for life. However, when the (initial) future 
life expectancy is only 10 years, which implies the hazard rate is $\lambda=0.10$, then under an $r=0.07$ interest rate, the cost of $\$ 1$ for life is only $1 / 0.17=5.88$ dollars. Equivalently, the payout per initial dollar of premium is 0.17 dollars per year.

In the deterministic case, we use the function $W(t)$ to denote the wealth at time $t$ of the retiree assuming she does not annuitize. Instead, she consumes a constant amount $c$ per year until she either runs out of money or she dies (whichever comes first). We quantify the dynamics of the wealth process and compute the probability she will run out of money while she is still alive. To simplify our work, we assume that there is only one interest rate $r$ in the economy (i.e., no term structure or expenses) and that all annuities are priced (fairly) as a function only of the hazard rate and interest rate (i.e., we ignore loading and expenses because these can be absorbed in the pricing hazard rate; see the discussion following (2.9)).

Formally, under a self-annuitization strategy, the wealth process of the retiree obeys the ordinary differential equation:

$$
d W(t)=(r W(t)-c) d t, \quad W(0)=1 .
$$

The individual retires with $\$ 1$ of wealth, invests at a rate of $r$, and consumes at a rate of $c$. Intuitively, therefore, wealth increases at the interest rate at which money is invested minus the consumption rate. The solution to this ordinary differential equation is

$$
W(t)=e^{r t}-c\left(\frac{e^{r t}-1}{r}\right), \quad t \leq t^{*},
$$

and 0 after time $t^{*}$, in which $t^{*}$ is the point at which the process hits zero (i.e., the individual is ruined). One can interpret this expression for $W(t)$ as the value at time $t$ of the initial $\$ 1$ minus the accumulated value of the continuous withdrawal due to consumption at rate $c$.

Now, assume the consumption rate is set equal to $c=\lambda+r$, which is the amount of life annuity income that $\$ 1$ will provide. In this self-annuitization case, the ruin time $t^{*}$, the point at which the function $W(t)$ reaches zero, equals

$$
t^{*}=\frac{1}{r} \ln \left(1+\frac{r}{\lambda}\right) \text {. }
$$

By substituting (2.6) into (2.1), we learn that the probability of surviving to the point at which the funds are exactly exhausted is

$$
\operatorname{Pr}\left[\tau_{d}>t^{*}\right]=\exp \left(-\lambda t^{*}\right)=\left(1+\frac{r}{\lambda}\right)^{-\frac{\lambda}{r}} .
$$

In Section 5.2, we contrast the probability of lifetime ruin in the deterministic case (2.7) with the probability of lifetime ruin when we allow random returns.

\subsection{Stochastic Returns}

In this subsection, we formalize the optimal annuity-purchasing and optimal investment problem for an individual who seeks to minimize the probability that she outlives her wealth. A priori, we allow the individual to buy annuities in lump sums or continuously, whichever is optimal. Our results are similar to those of Dixit and Pindyck (1994, pp. 359ff), which are given in the context of real options. They consider the problem of a firm's (irreversible) capacity expansion. In our model, annuity purchases are also irreversible, and this leads to the similarity in results. 
We assume that the individual can invest in a riskless asset whose price at time $s, X_{s}$, follows the process $d X_{s}=r X_{s} d s, X_{t}=x>0$, for some fixed $r \geq 0$, as in the previous subsection. However, unlike the previous subsection, the individual can also invest in a risky asset whose price at time $s, S_{s}$, follows geometric Brownian motion given by

$$
\left\{\begin{aligned}
d S_{s} & =\mu S_{s} d s+\sigma S_{s} d B_{s} \\
S_{t} & =S>0
\end{aligned}\right.
$$

in which $\mu>r, \sigma>0$, and $B_{s}$ is a standard Brownian motion with respect to a filtration $\left\{\mathcal{F}_{s}\right\}$ of the probability space $(\Omega, \mathcal{F}, \operatorname{Pr})$. Let $W_{s}$ be the wealth at time $s$ of the individual (after possibly purchasing annuities at that time), and let $\pi_{s}$ be the amount that the decision maker invests in the risky asset at time $s$. It follows that the amount invested in the riskless asset is $W_{s}-\pi_{s}$. Also, the decision maker consumes at a constant rate of $c$.

Our economy can be either real or nominal. When our model is interpreted in nominal terms, then the fixed consumption rate $c$ is nominal, and we assume that the individual buys annuities that pay a fixed nominal amount. In practice, of course, this exposes the retiree to inflation risk since $c$ today will buy much more than $c$ in 20 years. However, if $c$ is real, then we assume that the individual (only) has access to annuities that are indexed to inflation and thereby pay a fixed real amount. Also, in this case, the returns on the riskless and risky assets are stated in real returns. We prefer to think of the model in real terms, and our numerical examples are presented in real terms so that inflation risk, which would be a problem if $c$ were stated in nominal terms, is not an issue.

We employ a modified version of standard actuarial notation as in Bowers et al. (1997). We write $\lambda^{S}(t)$ to denote the individual-specific hazard rate at age $t$. Similarly, $\lambda^{O}$ denotes the objective hazard rate function used to price annuities. The actuarial present value of a life annuity that pays $\$ 1$ per year continuously to an individual aged $t$ based on the hazard rate function $\lambda^{O}$ is written $\bar{a}(t)$. The (objective) probability that our individual aged $t$ survives an additional $s$ years equals $\exp \left(-\int_{t}^{t+s} \lambda^{O}(u) d u\right)$. It is the analog of $e^{-\lambda s}$ in the case for which $\tau_{d}$ is exponentially distributed, as in (2.1). As in (2.2), to compute the actuarial present value of the life annuity, we discount the payment stream of $\$ 1$ per year by the interest rate $r$ and the hazard rate $\lambda^{O}$.

$$
\bar{a}(t)=\int_{0}^{\infty} e^{-r s} \exp \left(-\int_{t}^{t+s} \lambda^{O}(u) d u\right) d s .
$$

Throughout this paper, time coincides with the age of the individual; that is, at time $t$, the individual is age $t$. Note that the discount for mortality in (2.9) makes $\bar{a}(t)<1 / r$, the price of a perpetuity that pays $\$ 1$ per year continuously.

To clarify, by $\bar{a}(t)$, we mean the actual market price of the life annuity for an individual aged $t$. We deliberately refrain from discussing anti-selection, which creates the wedge between individual-specific and pricing (or objective) hazard rates. In addition, we omit actuarial loading fees, agent commissions, and other market imperfections that only add to the cost of annuities and can be absorbed in the pricing hazard rate.

The individual has a nonnegative income rate at time (or age) $s$ of $A_{s}$ after any annuity purchases at that time $\left(A_{s-}\right.$ before any annuity purchases at time $s$ ). Initial income could include Social Security benefits and defined benefit pension benefits, for example, but we assume that additional income only arises from buying life annuities by using money from current wealth. We assume that she can purchase a life annuity at the price of $\bar{a}(s)$ per dollar of annuity income at time $s$. Thus, wealth follows the process 


$$
\left\{\begin{aligned}
d W_{s} & =\left[r W_{s-}+(\mu-r) \pi_{s-}+A_{s-}-c\right] d s+\sigma \pi_{s-} d B_{s}-\bar{a}(s) d A_{s}, \\
W_{t} & =w \geq 0 \\
A_{t} & =A \geq 0 .
\end{aligned}\right.
$$

The negative sign for the subscript on the random processes denotes the left-hand limit of those quantities before any (lump sum) annuity purchases.

In order to reduce the number of variables in this problem, we define $X_{s}=c-A_{s}$. $X_{s}$ denotes the excess consumption that the individual requires; in other words, $X_{s}$ is the net consumption. By formulating the problem in terms of $X_{s}$, we will be able to reduce the dimension of the problem more easily in Section 4. With this new random variable, (2.10) becomes

$$
\left\{\begin{aligned}
d W_{s} & =\left[r W_{s-}+(\mu-r) \pi_{s-}-X_{s-}\right] d s+\sigma \pi_{s-} d B_{s}+\bar{a}(s) d X_{s}, \\
W_{t} & =w \geq 0 \\
X_{t} & =x \geq 0 .
\end{aligned}\right.
$$

We assume that the decision maker seeks to minimize, over admissible strategies $\left\{\pi_{s}, X_{s}\right\}$, her probability of lifetime ruin, namely, the probability that her wealth drops to zero before she dies. Admissible strategies $\left\{\pi_{s}, X_{s}\right\}$ are those that are measurable with respect to the information available at time $s$, namely $\mathcal{F}_{s}$, that restrict the excess consumption process $X$ to be nonnegative and nonincreasing (i.e., life annuity purchases are irreversible), and that result in (2.11) having a unique solution; see Karatzas and Shreve (1998), for example. Note that $\pi_{s}$ is unconstrained; thus, the investment in the risky asset can exceed current wealth (and often does, as we will see in Section 6.3). The individual values her probability of lifetime ruin via her specific hazard rate, while annuities are priced by using the objective hazard rate.

Denote the random time of death of our individual by $\tau_{d}$, as in the previous subsection, and the random time of lifetime ruin by $\tau_{0}$; that is, $\tau_{0}$ is the time at which wealth reaches zero. Thus, the probability of lifetime ruin $\psi$ for the individual at time $t$ defined on $\bar{D}=$ $\{(w, x, t): 0 \leq w \leq x \bar{a}(t), x \geq 0, t \geq 0\}$ is given by

$$
\psi(w, x, t)=\inf _{\left\{\pi_{s}, X_{s}\right\}} \operatorname{Pr}\left[\tau_{0}<\tau_{d} \mid W_{t}=w, X_{t}=x, \tau_{d}>t, \tau_{0}>t\right] .
$$

Note that if $w \geq x \bar{a}(t)$, then the individual can purchase an annuity that will guarantee her an income of $x=c-A$, which added to her income of $A$, gives her income to match her consumption rate of $c$. Thus, $\psi(w, x, t)=0$ for $w \geq x \bar{a}(t)$. If life annuities were not available, securing lifetime income would necessitate acquiring a perpetuity, which would cost $1 / r$ per $\$ 1$ of income, much more than the life annuity. This was the problem analyzed by Young (2004).

We continue with a formal derivation of the associated Hamilton-Jacobi-Bellman (HJB) variational inequality. First, note that the problem is one that combines continuous control (via the investment strategy $\pi_{s}$ ) and singular control (via the excess consumption strategy $X_{s}=c-A_{s}$ ). Indeed, suppose that we could write $d X_{s}=\chi_{s} d s$ for some rate $\chi_{s}$; that is, suppose that it is optimal to buy annuities at a continuous rate. Then, the HJB equation would contain a term of the form $\chi \bar{a}(t) \psi_{x}(w, x, t)$, which arises from (2.11), and that term would be minimized by setting $\chi=0$ or $\chi=\infty$ depending on the sign of $\psi_{x}$. Therefore, no such rate $\chi_{s}$ exists, and the problem of choosing the optimal excess consumption strategy is one of singular control; see Harrison and Taksar (1983) for an early relevant reference in mathematical finance. 
Now, suppose that at the point $(w, x, t)$, it is optimal not to purchase any annuities. It follows from Itô's lemma that $\psi$ satisfies the equation

$$
\lambda^{S}(t) \psi=\psi_{t}+(r w-x) \psi_{w}+\min _{\pi}\left[(\mu-r) \pi \psi_{w}+\frac{1}{2} \sigma^{2} \pi^{2} \psi_{w w}\right] .
$$

Because the above policy is in general suboptimal, (2.13) holds as an inequality; that is, for all $(w, x, t)$,

$$
\lambda^{S}(t) \psi \leq \psi_{t}+(r w-x) \psi_{w}+\min _{\pi}\left[(\mu-r) \pi \psi_{w}+\frac{1}{2} \sigma^{2} \pi^{2} \psi_{w w}\right] .
$$

Next, assume that at the point $(w, x, t)$, it is optimal to buy an annuity instantaneously. In other words, assume that the investor moves instantly from $(w, x, t)$ to $(w-\bar{a}(t) \Delta x, x-\Delta x, t)$, for some $\Delta x>0$. Then, the optimality of this decision implies that

$$
\psi(w, x, t)=\psi(w-\bar{a}(t) \Delta x, x-\Delta x, t),
$$

which in turns yields

$$
\bar{a}(t) \psi_{w}(w, x, t)+\psi_{x}(w, x, t)=0 .
$$

Note that the lump-sum purchase is such that (the negative of) the derivative of the probability of lifetime ruin with respect to excess consumption equals the adjusted derivative with respect to wealth, in which we adjust by the cost of $\$ 1$ of annuity income $\bar{a}(t)$. This is parallel to many results in economics. Indeed, the derivative of the probability of lifetime ruin with respect to excess consumption can be thought of as the marginal utility of the benefit, while the adjusted derivative with respect to wealth can be thought of as (the negative of) the marginal utility of the cost. We say "negative" here because $\psi$ is decreasing with respect to $w$. Thus, the lump-sum purchase forces the marginal utilities of benefit and cost to equal.

However, such a lump-sum purchasing policy is in general suboptimal; therefore, (2.16) holds as an inequality and becomes

$$
\bar{a}(t) \psi_{w}(w, x, t)+\psi_{x}(w, x, t) \leq 0 .
$$

By combining (2.14) and (2.17), we obtain the HJB variational inequality (2.18) below associated with the probability of ruin $\psi$ given in (2.12). The following result can be proved as in Zariphopoulou (1992), for example.

Proposition 2.1. The probability of lifetime ruin is a constrained viscosity solution of the Hamilton-Jacobi-Bellman variational inequality

$\max \left[\lambda^{S}(t) \psi-\psi_{t}-(r w-x) \psi_{w}-\min _{\pi}\left[(\mu-r) \pi \psi_{w}+\frac{1}{2} \sigma^{2} \pi^{2} \psi_{w w}\right], \bar{a}(t) \psi_{w}+\psi_{x}\right]=0$.

In the next section, we show that the barrier in (2.16) is the line $w=x \bar{a}(t)$; thus, the individual will annuitize when she has sufficient wealth to cover her shortfall of $x=$ $c-A$. If wealth and annuity income initially lie to the right of the barrier at time $t$, that is, $w \geq x \bar{a}(t)$, then the individual will immediately spend a lump sum of wealth to guarantee that the probability of lifetime ruin is zero. Otherwise, the annuity income is constant when wealth is low enough, that is, $w<x \bar{a}(t)$. Once wealth is high enough, that 
is, $w=x \bar{a}(t)$, the individual will spend her wealth to guarantee an income rate of $x+A=$ $c$ to match her consumption rate of $c$.

Thus, as in Dixit and Pindyck (1994, pp. 359ff) or in Zariphopoulou (1992), we have discovered that the optimal annuity-purchasing scheme is a type of barrier control. Other barrier control policies appear in finance and insurance. In finance, Zariphopoulou (1999, 2001) reviews the role of barrier policies in optimal investment in the presence of transaction costs; also see the references within her two articles. See Gerber (1979) for a classic text on risk theory in which he includes a section on optimal dividend payout and shows that it follows a type of barrier control. See Neuberger (2002) for an analysis that is similar to ours in the setting of maximizing expected utility of consumption.

\section{REDUCING THE DIMENSION OF THE MINIMIZATION PROBLEM}

In this section, we show that we can reduce the dimension of the variational inequality (2.18) by transforming the ruin probability $\psi(w, x, t)$ to a function of two variables. We also show that the barrier described by (2.16) corresponds with the line $w=x \bar{a}(t)$.

The probability of lifetime ruin $\psi$ is a function of the ratio $z=w / x$ and time $t$. Indeed, $\psi(w, x, t)=\psi(z, 1, t)$ by scaling the entire problem by $x=c-A$. This observation is also made in Milevsky and Robinson (2000), where the probability of lifetime ruin is shown to depend only on the ratio of current wealth to desired consumption. Davis and Norman (1990) and Shreve and Soner (1994) use a similar transformation in the problem of consumption and investment in the presence of transaction costs. Also, Duffie et al. (1997) and Koo (1998) use a similar transformation to study optimal consumption and investment with stochastic income.

Thus, define $V$ by

$$
V(z, t)=\psi(z, 1, t)
$$

so that $\psi(w, x, t)=V(z, t)$, from which it follows that $\psi_{t}=V_{t}, \psi_{w}=\frac{1}{x} V_{z}, \psi_{w w}=$ $\left(\frac{1}{x}\right)^{2} V_{z z}$, and $\psi_{x}=-\frac{z}{x} V_{z}$. Then, the barrier equation in (2.16) becomes

$$
z V_{z}=\bar{a}(t) V_{z}
$$

thus, either $V_{z}=0$ at the barrier or $z=\bar{a}(t)$ there. We now argue by contradiction that $V_{z} \neq 0$ at the barrier. Suppose that $V_{z}=0$ at the barrier; then, we can show that the barrier is given by $z=1 / r$. In other words, the individual buys no life annuities until her wealth is sufficient to buy a perpetuity to cover her excess consumption. However, note that (2.9) implies $\bar{a}(t)<1 / r$; that is, life annuities are cheaper than perpetuities. Thus, the individual's wealth will never reach $w=x / r$ because she will certainly buy an annuity when she has enough to cover her excess consumption (i.e., when $w=x \bar{a}(t)$ ) and thereby never ruin. Therefore, $z=\bar{a}(t)$ defines the barrier, and $z<\bar{a}(t)$ defines the region for which annuity buying is not optimal.

We have just shown that the individual will buy no annuities unless $w \geq x \bar{a}(t)$, in which case the individual will spend at least $x \bar{a}(t)$ to buy a life annuity to guarantee income of $x=c-A$ from the annuity. This income plus the income $A$ covers the consumption rate $c$, and the individual will not ruin. Therefore, the individual will not buy an annuity until she can guarantee that she will not ruin, a type of "bang-bang" strategy that results from the all-or-nothing nature of her goal.

We are now ready to give a complete formulation of the probability of lifetime ruin $\psi$. 
Proposition 3.1. The probability of lifetime ruin $\psi$ in (2.12) is given by

$$
\psi(w, x, t)=V(z, t) \text { if } z:=w / x<\bar{a}(t) \text {; otherwise, } \psi(w, x, t)=0,
$$

in which $V$ solves

$$
\lambda^{S}(t) V=V_{t}+(r z-1) V_{z}+\min _{\hat{\pi}}\left((\mu-r) \hat{\pi} V_{z}+\frac{1}{2} \sigma^{2} \hat{\pi}^{2} V_{z z}\right),
$$

for $z<\bar{a}(t)$, with boundary conditions $V(0, t)=1$ and $V(\bar{a}(t), t)=0$ and with transversality condition $\lim _{s \rightarrow \infty} \exp \left(-\int_{t}^{s} \lambda^{S}(u) d u\right) E\left[V\left(Z_{s}^{*}, s\right) \mid Z_{t}=z\right]=0$, in which $Z_{s}^{*}$ is the optimally controlled $Z_{s}$.

For a given set of controls, note that $Z_{s}$ equals the process $W_{s}$ when $x=1$. One can prove Proposition 3.1 formally by using an approach similar to the one in Harrison and Taksar (1983). In fact, the transversality condition arises from the (here-unstated) verification lemma underlying this proposition. In the next section, we show that (3.3) has a smooth solution in the classical sense.

\section{LINEARIZING THE EQUATION FOR $V$ VIA DUALITY ARGUMENTS}

In this section, we transform the nonlinear boundary-value problem in (3.3) to a linear free-boundary problem via the Legendre transform; see Karatzas and Shreve (1998). To this end, we first eliminate the $\lambda^{S}(t) V$ term from (3.3) by defining

$$
f(z, t)=\exp \left(-\int_{0}^{t} \lambda^{S}(u) d u\right) V(z, t) .
$$

It follows that (3.3) becomes

$$
f_{t}+(r z-1) f_{z}+\min _{\hat{\pi}}\left[(\mu-r) \hat{\pi} f_{z}+\frac{1}{2} \sigma^{2} \hat{\pi}^{2} f_{z z}\right]=0,
$$

with boundary conditions $f(0, t)=\exp \left(-\int_{0}^{t} \lambda^{S}(u) d u\right)$ and $f(\bar{a}(t), t)=0$ and with transversality condition $\lim _{s \rightarrow \infty} E\left[f\left(Z_{s}^{*}, s\right) \mid Z_{t}=z\right]=0$. This condition can be rewritten as $\lim _{t \rightarrow \infty} f(z, t)=0$ with probability 1 because $0 \leq f \leq 1$.

Next, consider the concave dual of $f$ defined via the Legendre transform by

$$
\tilde{f}(y, t)=\min _{z>0}[f(z, t)+z y] .
$$

The critical value $z^{*}$ solves the equation $f_{z}(z, t)+y=0$; thus, $z^{*}=I(-y, t)$, in which $I$ is the inverse of $f_{z}$ with respect to $z$. It follows that

$$
\tilde{f}(y, t)=f[I(-y, t), t]+y I(-y, t) .
$$

Note that

$$
\begin{aligned}
\tilde{f}_{y}(y, t) & =-f_{z}[I(-y, t)] I_{y}(-y, t)+I(-y, t)-y I_{y}(-y, t) \\
& =y I_{y}(-y, t)+I(-y, t)-y I_{y}(-y, t) \\
& =I(-y, t) .
\end{aligned}
$$

We can retrieve the function $f$ from $\tilde{f}$ by the relationship

$$
f(z, t)=\max _{y>0}[\tilde{f}(y, t)-z y] .
$$

Indeed, the critical value $y^{*}$ solves the equation $\tilde{f}_{y}(y, t)-z=0$; thus, $y^{*}=-f_{z}(z, t)$, and 


$$
\begin{aligned}
\tilde{f}\left(y^{*}, t\right)-z y^{*} & =f\left[I\left(-y^{*}, t\right), t\right]+y^{*} I\left(-y^{*}, t\right)-z y^{*} \\
& =f\left[I\left(f_{z}(z, t), t\right), t\right]-f_{z}(z, t) I\left(f_{z}(z, t), t\right)+z f_{z}(z, t) \\
& =f(z, t)-z f_{z}(z, t)+z f_{z}(z, t) \\
& =f(z, t),
\end{aligned}
$$

in which we use equation (4.3) for the first equality.

Next, note that

$$
\tilde{f}_{y y}(y, t)=-I_{y}(-y, t)=-1 / f_{z z}[I(-y, t), t]
$$

and

$$
\begin{aligned}
\tilde{f}_{t}(y, t) & =f_{z}[I(-y, t), t] I_{t}(-y, t)+f_{t}[I(-y, t), t]+y I_{t}(-y, t) \\
& =-y I_{t}(-y, t)+f_{t}[I(-y, t), t]+y I_{t}(-y, t) \\
& =f_{t}[I(-y, t), t] .
\end{aligned}
$$

In the partial differential equation for $f$, let $z=I(-y, t)$ to obtain

$$
f_{t}[I(-y, t), t]+(r I(-y, t)-1) f_{z}[I(-y, t), t]-\frac{1}{2}\left(\frac{\mu-r}{\sigma}\right)^{2} \frac{\left(f_{z}[I(-y, t), t]\right)^{2}}{f_{z z}[I(-y, t), t]}=0 .
$$

Rewrite this equation in terms of $\tilde{f}$ to get

$$
\tilde{f}_{t}(y, t)+(r I(-y, t)-1)(-y)-m \frac{(-y)^{2}}{-1 / \tilde{f}_{y y}(y, t)}=0,
$$

in which $m=\frac{1}{2}\left(\frac{\mu-r}{\sigma}\right)^{2}$, or equivalently,

$$
\tilde{f}_{t}(y, t)-r y \tilde{f}_{y}(y, t)+m y^{2} \tilde{f}_{y y}(y, t)+y=0,
$$

with boundary conditions given implicitly by $f(0, t)=\exp \left(-\int_{0}^{t} \lambda^{S}(u) d u\right)$ and $f(\bar{a}(t), t)=0$.

Now, consider the boundary conditions $f(0, t)=\exp \left(-\int_{0}^{t} \lambda^{S}(u) d u\right)$ and $f(\bar{a}(t), t)=$ 0 . Because $f_{z}<0$ is strictly increasing with respect to $z$, we have $y_{0}(t)>y_{b}(t) \geq 0$ for all $t \geq 0$, in which $y_{0}(t)$ and $y_{b}(t)$ are defined by

$$
y_{0}(t)=-f_{z}(0, t)
$$

and

$$
y_{b}(t)=-f_{z}(\bar{a}(t), t) .
$$

We use subscript 0 to denote the point corresponding to wealth equal to 0 , and we use subscript $b$ to denote the point corresponding to the value of wealth at which the individual buys a life annuity.

Thus, the boundary conditions become

$$
\tilde{f}\left(y_{0}(t), t\right)=\exp \left(-\int_{0}^{t} \lambda^{S}(u) d u\right), \text { for } \tilde{f}_{y}\left(y_{0}(t), t\right)=0,
$$

and

$$
\tilde{f}\left(y_{b}(t), t\right)=\bar{a}(t) y_{b}(t), \text { for } \tilde{f}_{y}\left(y_{b}(t), t\right)=\bar{a}(t) .
$$

The transversality condition $\lim _{t \rightarrow \infty} f(z, t)=0$ becomes $\lim _{t \rightarrow \infty} \tilde{f}(y, t)=0$. Note that the first equations in (4.11) and (4.12) are reminiscent of value matching conditions, while the second equations are reminiscent of smooth pasting conditions. We exploit this observation in Section 6, where we express $\tilde{f}$ as the value function for an optimal stopping problem. Thus, we are able to solve the free-boundary problem numerically. 
Before pursuing this numerical method, we obtain an exact solution for $\psi$ in a special case in Section 5.

\section{SOLUTION OF THE FREE-BOUNDARY PROBLEM FOR A SPECIAL CASE: CONSTANT HAZARD RATE}

Throughout this section, we assume that the forces of mortality are constant; that is, that $\lambda^{S}(t) \equiv \lambda^{S}$ and $\lambda^{O}(t) \equiv \lambda^{O}$ for all $t \geq 0$. In this case, the ruin probability $\psi$ is independent of time, and the partial differential equation in (3.3) is an ordinary differential equation. We use this time-homogeneity to compute a "implicit" analytical solution of $\psi$.

\subsection{Solution of the Boundary-Value Problem}

If we assume that the forces of mortality are constant, (3.3) becomes the ordinary differential equation:

$$
\lambda^{S} V=(r z-1) V^{\prime}+\min _{\hat{\pi}}\left((\mu-r) \hat{\pi} V^{\prime}+\frac{1}{2} \sigma^{2} \hat{\pi}^{2} V^{\prime \prime}\right),
$$

with boundary conditions $V(0)=1$ and $V\left(1 /\left(r+\lambda^{O}\right)\right)=0$.

If we define the concave dual of $V$ by $\tilde{V}(n)=\min _{z>0}[V(z)+z n]$, as in Section 4, then we obtain the following free-boundary problem for $\tilde{V}$ :

$$
-\lambda^{S} \tilde{V}(n)-\left(r-\lambda^{S}\right) n \tilde{V}^{\prime}(n)+m n^{2} \tilde{V}^{\prime \prime}(n)+n=0,
$$

with boundary conditions

$$
\tilde{V}\left(n_{0}\right)=1, \quad \text { for } \tilde{V}^{\prime}\left(n_{0}\right)=0
$$

and

$$
\tilde{V}\left(n_{b}\right)=\frac{n_{b}}{r+\lambda^{O}}, \quad \text { for } \tilde{V}^{\prime}\left(n_{b}\right)=\frac{1}{r+\lambda^{O}} .
$$

The general solution of (5.2) is

$$
\tilde{V}(n)=D_{1} n^{B_{1}}+D_{2} n^{B_{2}}+\frac{n}{r}
$$

with $D_{1}$ and $D_{2}$ constants determined by the boundary conditions, and with $B_{1}$ and $B_{2}$ given by

$$
B_{1}=\frac{1}{2 m}\left[\left(r-\lambda^{S}+m\right)+\sqrt{\left(r-\lambda^{S}+m\right)^{2}+4 m \lambda^{S}}\right]>1,
$$

and

$$
B_{2}=\frac{1}{2 m}\left[\left(r-\lambda^{S}+m\right)-\sqrt{\left(r-\lambda^{S}+m\right)^{2}+4 m \lambda^{S}}\right]<0 .
$$

The boundary conditions at $n_{b}$ give us

$$
D_{1} n_{b}^{B_{1}}+D_{2} n_{b}^{B_{2}}+\frac{n_{b}}{r}=\frac{n_{b}}{r+\lambda^{O}}
$$

and

$$
D_{1} B_{1} n_{b}^{B_{1}}+D_{2} B_{2} n_{b}^{B_{2}}+\frac{n_{b}}{r}=\frac{n_{b}}{r+\lambda^{O}} .
$$

Solve equations (5.8) and (5.9) to get $D_{1}$ and $D_{2}$ in terms of $n_{b}$ :

$$
D_{1}=-\frac{\lambda^{O}}{r\left(r+\lambda^{O}\right)} \frac{1-B_{2}}{B_{1}-B_{2}} n_{b}^{1-B_{1}}<0,
$$

and 


$$
D_{2}=-\frac{\lambda^{O}}{r\left(r+\lambda^{O}\right)} \frac{B_{1}-1}{B_{1}-B_{2}} n_{b}^{1-B_{2}}<0
$$

Next, substitute for $D_{1}$ and $D_{2}$ in the second equation in (5.3), namely $D_{1} B_{1} n_{0}^{B_{1}-1}+$ $D_{2} B_{2} n_{0}^{B_{2}-1}+\frac{1}{r}=0$, to get

$$
\frac{\lambda^{O}}{r+\lambda^{O}} \frac{B_{1}\left(1-B_{2}\right)}{B_{1}-B_{2}}\left(\frac{n_{0}}{n_{b}}\right)^{B_{1}-1}+\frac{\lambda^{O}}{r+\lambda^{O}} \frac{B_{2}\left(B_{1}-1\right)}{B_{1}-B_{2}}\left(\frac{n_{0}}{n_{b}}\right)^{B_{2}-1}=1 .
$$

Equation (5.12) gives us an equation for the ratio $n_{0} / n_{b}>1$. To check that (5.12) has a unique solution greater than 1 , note that the left-hand side (1) equals $\lambda^{O} /\left(r+\lambda^{O}\right)<1$ when we set $n_{0} / n_{b}=1$, (2) goes to infinity as $n_{0} / n_{b}$ goes to infinity, and (3) is strictly increasing with respect to $n_{0} / n_{b}$.

Next, substitute for $D_{1}$ and $D_{2}$ in the first equation in (5.3), namely $D_{1} n_{0}^{B_{1}-1}+$ $D_{2} n_{0}^{B_{2}-1}+\frac{1}{r}=\frac{1}{n_{0}}$ to get

$$
-\frac{\lambda^{O}}{r\left(r+\lambda^{O}\right)} \frac{1-B_{2}}{B_{1}-B_{2}}\left(\frac{n_{0}}{n_{b}}\right)^{B_{1}-1}-\frac{\lambda^{O}}{r\left(r+\lambda^{O}\right)} \frac{B_{1}-1}{B_{1}-B_{2}}\left(\frac{n_{0}}{n_{b}}\right)^{B_{2}-1}+\frac{1}{r}=\frac{1}{n_{0}} .
$$

Substitute for $n_{0} / n_{b}$ in equation (5.13), and solve for $n_{0}$. Finally, we can get $n_{b}$ from

$$
n_{b}=\frac{n_{0}}{n_{0} / n_{b}}
$$

and $D_{1}$ and $D_{2}$ from equations (5.10) and (5.11), respectively.

Once we have the solution for $\tilde{V}$, we can recover $V$ by

$$
\begin{aligned}
V(z) & =\max _{n>0}[\tilde{V}(n)-z n] \\
& =\max _{n>0}\left[D_{1} n^{B_{1}}+D_{2} n^{B_{2}}+\frac{n}{r}-z n\right],
\end{aligned}
$$

in which the critical value $n^{*}$ solves

$$
D_{1} B_{1} n^{B_{1}-1}+D_{2} B_{2} n^{B_{2}-1}+\frac{1}{r}=z .
$$

Thus, for a given value of $z=w / x$, solve (5.16) for $n$ and plug that value of $n$ into (5.15) to get $\psi(w, x)=V(z)$.

Also of interest is the amount invested in the risky asset, especially as wealth approaches the annuitization level $x /\left(r+\lambda^{O}\right)$.

$$
\pi^{*}(w, x)=x \hat{\pi}^{*}(z)=-x \frac{\mu-r}{\sigma} \frac{V^{\prime}(z)}{V^{\prime \prime}(z)}=-x \frac{\mu-r}{\sigma} n \tilde{V}^{\prime \prime}(n) .
$$

Now, $n \tilde{V}^{\prime \prime}(n)=D_{1} B_{1}\left(B_{1}-1\right) n^{B_{1}-1}+D_{2} B_{2}\left(B_{2}-1\right) n^{B_{2}-1}$, so after substituting for $D_{1}$ and $D_{2}$ from equations (5.10) and (5.11), respectively, the optimal investment in the risky asset (in terms of $n$ ) becomes

$$
\left.x \hat{\pi}^{*}(z)\right|_{z=I(-n)}=x \frac{\mu-r}{\sigma} \frac{\lambda^{O}}{r\left(r+\lambda^{O}\right)} \frac{\left(B_{1}-1\right)\left(1-B_{2}\right)}{B_{1}-B_{2}}\left[B_{1}\left(\frac{n}{n_{b}}\right)^{B_{1}-1}-B_{2}\left(\frac{n}{n_{b}}\right)^{B_{2}-1}\right] .
$$

In particular, as $n$ approaches $n_{b}$, the point at which the individual annuitizes all her wealth, the amount invested in the risky asset approaches 


$$
x \frac{2 r}{\mu-r}\left(\frac{1}{r}-\frac{1}{r+\lambda^{O}}\right),
$$

independent of $\sigma$ and $\lambda^{S}$. Note that the expression in (5.18) is a multiple of the difference between the cost of the perpetuity and the cost of the annuity.

In addition to the amount invested in the risky asset, it is useful to know how that amount changes as one's wealth changes. Note that the derivative of $\pi^{*}(w, x)$ with respect to $w$ has the same sign as the derivative of $n \tilde{V}^{\prime \prime}(n)$ with respect to $n$. Thus, the amount of wealth invested in the risky asset decreases with respect to wealth if and only if

$$
n \tilde{V}^{\prime \prime \prime}(n)+\tilde{V}^{\prime \prime}(n)<0 \text { for all } n \in\left(n_{b}, n_{0}\right)
$$

After some elementary algebra, we determine that (5.19) holds if $\lambda^{S}<r$, while if $\lambda^{S}$ is sufficiently larger than $r$, then the amount of wealth invested in the risky asset increases with wealth, as we will see in the example in the next section.

\subsection{Numerical Examples}

In this section, we present numerical examples to demonstrate the results of Section 5.1. We will calculate the probability of lifetime ruin $\psi(w, x)$ in the presence of annuities with the corresponding probability $\psi_{0}(w, x)$ when the individual cannot buy annuities, the problem studied in Young (2004). From that work, we know that the probability of lifetime ruin $\psi_{0}(w, x)$ is given by

$$
\psi_{0}(w, x)=(1-r z)^{p}, \text { for } 0 \leq z<\frac{1}{r}, \quad 0 \leq z \leq 1 / r,
$$

in which $z=w / x$, and $p=\frac{1}{2 r}\left[\left(r+\lambda^{S}+m\right)+\sqrt{\left(r+\lambda^{S}+m\right)^{2}-4 r \lambda^{S}}\right]>1$. Also, the corresponding optimal investment in the risky asset $\pi_{0}^{*}(w, x)$ is given by

$$
\pi_{0}^{*}(w, x)=\frac{\mu-r}{\sigma} \cdot \frac{1-r z}{r(p-1)}, \quad 0 \leq z \leq 1 / r .
$$

Note that in this case, the probability of lifetime ruin is 0 when $z \geq 1 / r$ because when (relative) wealth is that large, then the individual can invest all her income in the riskless asset and fund her consumption with the earnings from that asset. Also, note that $\pi_{0}^{*}$ approaches 0 as $z$ approaches $1 / r$. From (5.18), we know that $\pi^{*}$ does not approach 0 as $z$ approaches $\bar{a}(t)$ when life annuities are available in the market.

EXAMPLE 5.1. Constant Real Dollar Consumed: Suppose we have the following values of the parameters:

- $\lambda^{S}=\lambda^{O}=0.04$; the hazard rate is constant such that the expected future lifetime is 25 years.

- $r=0.02$; the riskless rate of return is $2 \%$ over inflation.

- $\mu=0.06$; the drift of the risky asset is $6 \%$ over inflation.

- $\sigma=0.20$; the volatility of the risky asset is $20 \%$.

- $c=1$; the individual consumes one unit of wealth per year.

- $A=0$; without loss of generality, we assume that annuity income is zero.

It follows that the excess consumption $x=c-A=1$ and that $z=w / x=w$. The cost of the annuity is $1 /\left(r+\lambda^{O}\right)=1 / 0.06=\$ 16.6 \overline{6}$, while the cost of the perpetuity much larger at $1 / r=1 / 0.02=\$ 50.00$. In this example, $D_{1}=-103.4, D_{2}=-0.002642, n_{0}=$ 0.081 , and $n_{b}=0.044$. In Table 5.1, we give the probabilities of ruin $\psi$ and $\psi_{0}$ and the corresponding optimal investments in the risky asset, $\pi^{*}$ and $\pi_{0}^{*}$, respectively. 
TABLE 5.1

Probability of Lifetime Ruin and Optimal Investment in Risky Asset

\begin{tabular}{llccc}
\hline$w$ & $\psi(w, 1)$ & $\pi^{*}(w, 1)$ & $\psi_{0}(w, 1)$ & $\pi_{0}^{*}(w, 1)$ \\
\hline 0.0 & 1.000 & 25.283 & 1.000 & 20.711 \\
0.5 & 0.960 & 25.300 & 0.966 & 20.504 \\
1.0 & 0.921 & 25.327 & 0.933 & 20.296 \\
2.0 & 0.844 & 25.415 & 0.870 & 19.882 \\
5.0 & 0.633 & 25.977 & 0.698 & 18.640 \\
7.5 & 0.474 & 26.829 & 0.574 & 17.604 \\
10.0 & 0.330 & 28.066 & 0.467 & 16.569 \\
12.0 & 0.223 & 29.345 & 0.392 & 15.740 \\
14.0 & 0.123 & 30.885 & 0.326 & 14.912 \\
16.0 & 0.030 & 32.680 & 0.268 & 14.083 \\
16.5 & 0.0074 & 33.168 & 0.255 & 13.876 \\
16.6 & 0.00296 & 33.267 & 0.252 & 13.835 \\
16.66 & 0.000296 & 33.327 & 0.251 & 13.810 \\
16.666 & 0.0000296 & 33.333 & 0.251 & 13.807 \\
20.0 & 0.000 & n.a. & 0.175 & 12.426 \\
\hline
\end{tabular}

There are a variety of interesting lessons that can be gleaned from the numbers in Table 5.1. First, for very low values of wealth, the probability of lifetime ruin is (obviously) close to $100 \%$, but it is quite insensitive to whether or not annuities are available. Intuitively, the reason is that the costs of the annuity and the perpetuity are both relatively far from current wealth and are therefore probabilistically inaccessible. However, as the value of wealth increases, the probability of lifetime ruin declines, and the rate of probability improvement is much higher when the life annuity is available. In fact, as we get very close to the cost of the life annuity, $\$ 16.6 \overline{6}$, the probability of lifetime ruin approaches zero - since as soon as that level is reached the entire wealth will be annuitized - while the cost of the perpetuity is still a distance away at $\$ 50.00$.

As predicted by equation (5.18), as wealth approaches the cost of the life annuity, the equity allocation moves toward $33.3 \overline{3}=50.00-16.6 \overline{6}$, the difference between the cost of the perpetuity and the cost of an annuity. Another use of the results in Table 5.1 is to invert the $\psi$ function and solve for the current level of wealth-to-consumption needed to maintain a lifetime ruin probability under some pre-specified level. Thus, for example, if the retiree is interested in having at least a 95\% chance of lifetime consumption survival - which implies at most a 5\% probability of lifetime ruin - then she must have wealth of at least 15.55 times her desired consumption.

Note from Table 5.1, that $\psi(w, x)<\psi_{0}(w, x)$, as expected, because the probability of lifetime ruin should be less when the individual's investment opportunities expand to include annuities. On the other hand, the optimal investment in the risky asset increases with respect to wealth in the presence of annuities for this particular example (i.e., $\lambda^{S}=$ 0.04 is sufficiently larger than $r=0.02$ ), but it decreases when the individual cannot buy annuities. Young (2004) showed the latter, but $\pi^{*}$ might increase or decrease when the individual can buy annuities, depending on the magnitude of $\lambda^{S}$ relative to $r$; see the discussion immediately following (5.19). Note also that we have $\pi^{*}(w, 1)>w$ for some values of wealth; thus, the individual borrows in order to invest in the risky asset. In 
particular, at the lower wealth levels, the optimal strategy is a heavily leveraged position in the risky asset. This occurs because $\pi$ is unconstrained and also perhaps because of the binary nature of the investor's goal. We comment on the constrained problem in Section 7.

EXAMPLE 5.2. Benefit of Dynamic Portfolio Management and Annuity Purchase: Recall that in Section 2.1, we computed the probability of lifetime ruin under the assumption of exponential future lifetime for an individual with wealth $\$ 1$ who invests in the riskless asset only and self-annuitizes, that is, who consumes $c=\lambda+r$ per year, the amount of life-annuity income that $\$ 1$ would provide. In this example, we quantify the benefit of dynamic portfolio management and the purchase of a life annuity by computing the probability of lifetime ruin for an individual who consumes $c=\lambda+r$ per year and by contrasting the results with those of Section 2.1.

As in Example 5.1, we choose $\lambda^{S}=\lambda^{O}=\lambda=0.04, r=0.02, \mu=0.06$, and $\sigma=0.2$. In the deterministic case, an individual with initial wealth $\$ 1$ who self-annuitizes consumes $c=\lambda+r=0.06$ per year. By the results of Section 2.1, namely equation (2.7), we have that the ruin probability is $\left(1+\frac{r}{\lambda}\right)^{-\frac{\lambda}{r}}=0.4444$.

If life annuities are available, an investor with wealth $\$ 1$ can purchase a life annuity to provide the desired income $c=\lambda+r$; therefore, the probability of lifetime is zero when wealth equals $\$ 1$. Moreover, Figure 5.1 shows that $\psi(w, 0.06)<0.444$ for

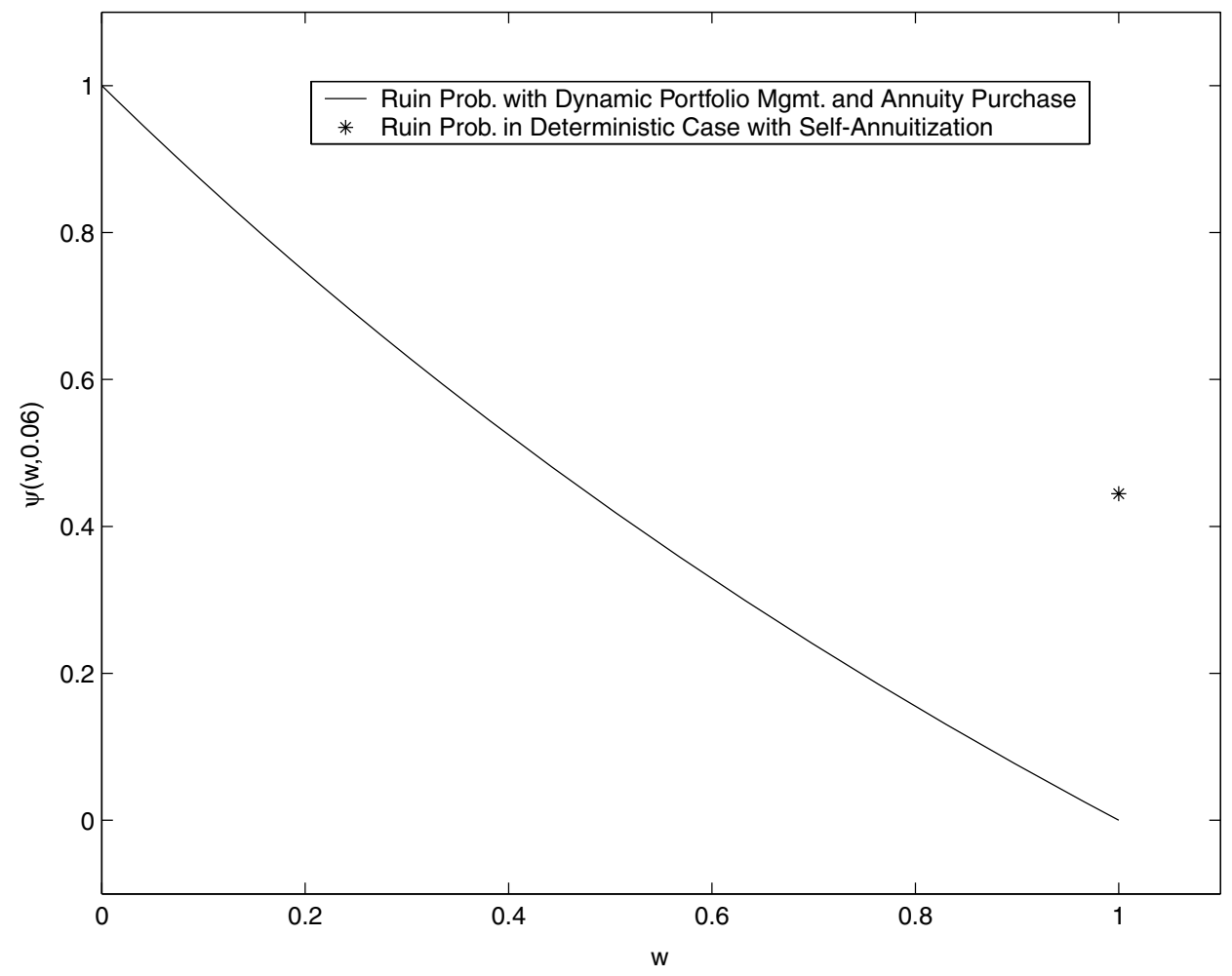

FIGURE 5.1. With dynamic portfolio management and life annuity purchasing, an individual can maintain the same consumption level with lower ruin probabilities, even with lower wealth. 
$w \in(0.5,1)$. Thus, dynamic portfolio management and a life annuity purchase yield lower ruin probabilities, even with lower wealth.

\section{SOLUTION OF THE FREE-BOUNDARY PROBLEM: GENERAL HAZARD RATE}

In the previous section, we observed that if we assume constant hazard rate, we can derive an implicit analytical solution to the free-boundary problem. Under more general mortality assumptions, there is no implicit analytical solution to the free-boundary problem given by (4.8), (4.11), and (4.12).

In this section, we exploit the connection between solutions of free-boundary problems and value functions for optimal stopping problems (Øksendal 1998). We recast our free-boundary problem as a variational inequality for the value function of an optimal stopping problem.

We employ the projected SOR method (Wilmott, Dewynne, and Howison 2000) to calculate the solution of the free-boundary problem numerically. We check that in the case of constant force of mortality, the results of our numerical method agree with those in Example 5.1. We, then, consider several examples in which we examine the effect on the ruin probability and on the optimal investment strategy of changing the mortality assumptions and the parameters of the financial model.

\subsection{Optimal Stopping Formulation}

In this section, we propose an optimal stopping problem whose value function $\hat{f}$ corresponds with the solution $\tilde{f}$ of the free-boundary problem (4.8), (4.11), and (4.12). Equations (4.11) and (4.12) motivate us to define a penalty function $u$ by

$$
u(y, t)=\min \left(\exp \left(-\int_{0}^{t} \lambda^{S}(v) d v\right), \bar{a}(t) y\right) .
$$

We consider this function because it is maximal among those functions that are concave in $y$ and satisfy the boundary conditions in (4.11) and (4.12). Recall that $\tilde{f}$ is concave and increasing in $y$. Thus, $\tilde{f}(y, t) \leq u(y, t)$ for all $(y, t)$ such that $y_{b}(t) \leq y \leq y_{0}(t)$.

Define a stochastic process $Y_{s}$ by

$$
\left\{\begin{aligned}
d Y_{s} & =-r Y_{s}+\frac{\mu-r}{\sigma} Y_{s} d \tilde{B}_{s} \\
Y_{t} & =y>0 .
\end{aligned}\right.
$$

Finally, consider the optimal stopping problem given by

$$
\hat{f}(y, t)=\inf _{\tau} E\left[\int_{t}^{\tau} Y_{s} d s+u\left(Y_{\tau}, \tau\right) \mid Y_{t}=y\right] .
$$

One can think of this problem as awarding a "player" the running penalty $Y_{s}$ between time $t$ and the time of stopping $\tau$. At the time of stopping, the player receives the penalty $u\left(Y_{\tau}, \tau\right)$. Thus, at each point in time, the player has to decide whether it is better to continue receiving the running penalty $Y_{s}$ or to stop and take the final penalty $u\left(Y_{\tau}, \tau\right)$.

By Øksendal (1998, Chapter 10), the value function $\hat{f}$ of the optimal stopping problem solves the variational inequality

$$
\max \left[-\hat{f}_{t}+r y \hat{f}_{y}-m y^{2} \hat{f}_{y y}-y, \hat{f}-u\right]=0,
$$


If the variational inequality in (6.4) has a smooth solution, then it is the smooth solution of the free-boundary problem given by (4.8), (4.11), and (4.12), which in turn is the transformed smooth solution of (3.3). Friedman and Shen (2002) prove the existence of a unique, continuous solution to a similar variational inequality; they prove that this solution has locally bounded derivatives.

Øksendal (1998, Section 10.4) studies such optimal stopping problems and proves a verification theorem that we can apply as follows: If we can show that

$$
u_{t}(y, t)-r y u_{y}(y, t)+m y^{2} u_{y y}(y, t)+y \geq 0,
$$

for $y>y_{0}(t)$ and for $y<y_{b}(t)$, and if $\tilde{f}$ is sufficiently regular, then $\hat{f}=\tilde{f}$. Thus, to numerically solve for $\tilde{f}$, we can use algorithms developed for optimal stopping problems and solve for $\hat{f}$, the value function of the optimal stopping problem.

It remains for us to verify that inequality (6.5) holds. Indeed, for $y<y_{b}(t)$, we have that $u(y, t)=\bar{a}(t) y$, so that

$$
\begin{aligned}
& u_{t}(y, t)-r y u_{y}(y, t)+m y^{2} u_{y y}(y, t)+y \\
& \quad=\left[-1+\left(r+\lambda^{O}(t)\right) \bar{a}(t)\right] y-r y \bar{a}(t)+y \\
& \quad=\lambda^{O}(t) \bar{a}(t) y \geq 0,
\end{aligned}
$$

so (6.5) holds here. For $y>y_{0}(t)$, we have that $u(y, t)=\exp \left(-\int_{0}^{t} \lambda^{S}(v) d v\right)$, so that

$$
u_{t}(y, t)-r y u_{y}(y, t)+m y^{2} u_{y y}(y, t)+y=-\lambda^{S}(t) \exp \left(-\int_{0}^{t} \lambda^{S}(v) d v\right)+y,
$$

and this expression is nonnegative for all $y>y_{0}(t)$ if and only if

$$
y_{0}(t) \geq \lambda^{S}(t) \exp \left(-\int_{0}^{t} \lambda^{S}(v) d v\right) .
$$

Inequality (6.8) holds if the hazard rate used in pricing $\lambda^{O}(t)$ is increasing with respect to age, and if $\lambda^{S}(t) \leq r+\lambda^{O}(t)$. Indeed, $y_{0}(t)=-f_{z}(0, t)$. By convexity of $f$, the slope of $f$ at the point $\left(0, \exp \left(-\int_{0}^{t} \lambda^{S}(v) d v\right)\right)$ is less than the slope of the secant from the point $\left(0, \exp \left(-\int_{0}^{t} \lambda^{S}(v) d v\right)\right)$ to the point $(\bar{a}(t), 0)$. That is, $f_{z}(0, t) \leq$ $-\exp \left(-\int_{0}^{t} \lambda^{S}(v) d v\right) / \bar{a}(t)$, which implies that

$$
y_{0}(t) \geq \exp \left(-\int_{0}^{t} \lambda^{S}(v) d v\right) / \bar{a}(t) \geq \lambda^{S}(t) \exp \left(-\int_{0}^{t} \lambda^{S}(v) d v\right)
$$

because $\lambda^{O}(t)$ is increasing.

\subsection{The Numerical Method}

In this section, we briefly describe the numerical treatment of the variational inequality (6.4). Because (6.4) is similar to the variational inequality associated with pricing an American option, we employ the projected SOR method, as described in Wilmott, Dewynne, and Howison (2000), to find the solution $\hat{f}$ of (6.4) and to recover the free boundary. The projected SOR method is an iterative method for solving the partial differential equation from (6.4), namely,

$$
-\hat{f}_{t}(y, t)+r y \hat{f}_{y}(y, t)-m y^{2} \hat{f}_{y y}(y, t)-y=0, \quad y \in\left(y_{b}(t), y_{0}(t)\right),
$$

subject to the inequality constraint from (6.4), namely, 


$$
\hat{f}(y, t) \leq u(y, t), \quad y \in\left(y_{b}(t), y_{0}(t)\right) .
$$

We solve the constrained partial differential equation on a domain that properly contains the free boundary and then recover the location of the free boundary after computing the solution. The boundary points $y_{b}(t)$ and $y_{0}(t)$ are the points at which the inequality in (6.11) changes to equality. Øksendal (1998, Section 10.4) ensures that $\hat{f}$ also solves the free-boundary problem (4.8), (4.11), and (4.12).

To employ the projected SOR method, we

1. Transform the degenerate problem in $(6.10)$ and $(6.11)$ on $(0, \infty)$ to a nondegenerate problem on $\mathcal{R}$ via the standard transformation $\xi=\ln y$.

2. Solve the transformed variational inequality via the projected SOR method and recover the location of the free boundary.

3. Invert the dual transform as in Section 5 to recover $V(z, t)$ from $\hat{f}(z, t)$.

4. Numerically approximate the optimal investment in the risky asset $\pi^{*}(z, t)$.

We tested this numerical scheme by using it to calculate the probability of lifetime ruin and the corresponding optimal investment strategy for the scenario in Example 5.1 with constant hazard rate. Our computed solution matched those given in Example 5.1, so we are confident in the validity of our numerical scheme.

\subsection{Examples}

In this section, we consider several examples. We begin with a base scenario and then examine the effect on the ruin probability and optimal investment strategy of changing the mortality assumptions and the parameters of the financial model. We take the following as our base scenario:

\section{Base Scenario:}

- Consistent with the mortality assumptions in Milevsky and Young (2003) and Huang, Milevsky, and Wang (2004), we use the Gompertz hazard rate $\lambda^{O}(t)=$ $\exp \left(\frac{t-\bar{m}}{b}\right) / b$, where $\bar{m}$ is a modal value and $b$ is a scale parameter. Note that the hazard rate increases exponentially with age. We choose $\bar{m}=90$ and $b=9$. Also, let $\lambda^{S}(t)=\lambda^{O}(t)+\eta$, where $\eta$ is a parameter that quantifies the individual's mortality relative to the pricing mortality. To begin, we let $\eta=0$.

- $t=50$; the investor is 50 years old.

- $r=0.02$; the riskless rate of return is $2 \%$ over inflation.

- $\mu=0.06$; the drift on the risky asset is $6 \%$ over inflation.

- $\sigma=0.20$; the volatility of the risky asset is $20 \%$.

- $c=1$; the individual consumes one unit of wealth per year.

- $A=0$; without loss of generality, we assume that annuity income is zero. It follows that $x=c-A=1$, and $z=w / x=w$.

In the experiments that follow, we examine the impact on the ruin probability and optimal investment strategy of varying individual parameters from the values given above.

EXAMPLE 6.1. Impact of Attained Age: Figure 6.1 shows the ruin probability $\psi(w$, $1, t)$ and optimal investment in the risky asset $\pi^{*}(w, 1, t)$ for the base scenario described above (i.e., for $t=50$ ) as well as for ages $t=30$ and 70 . We note that the ruin probability and optimal investment in the risky asset decrease as age increases. Thus, a younger 

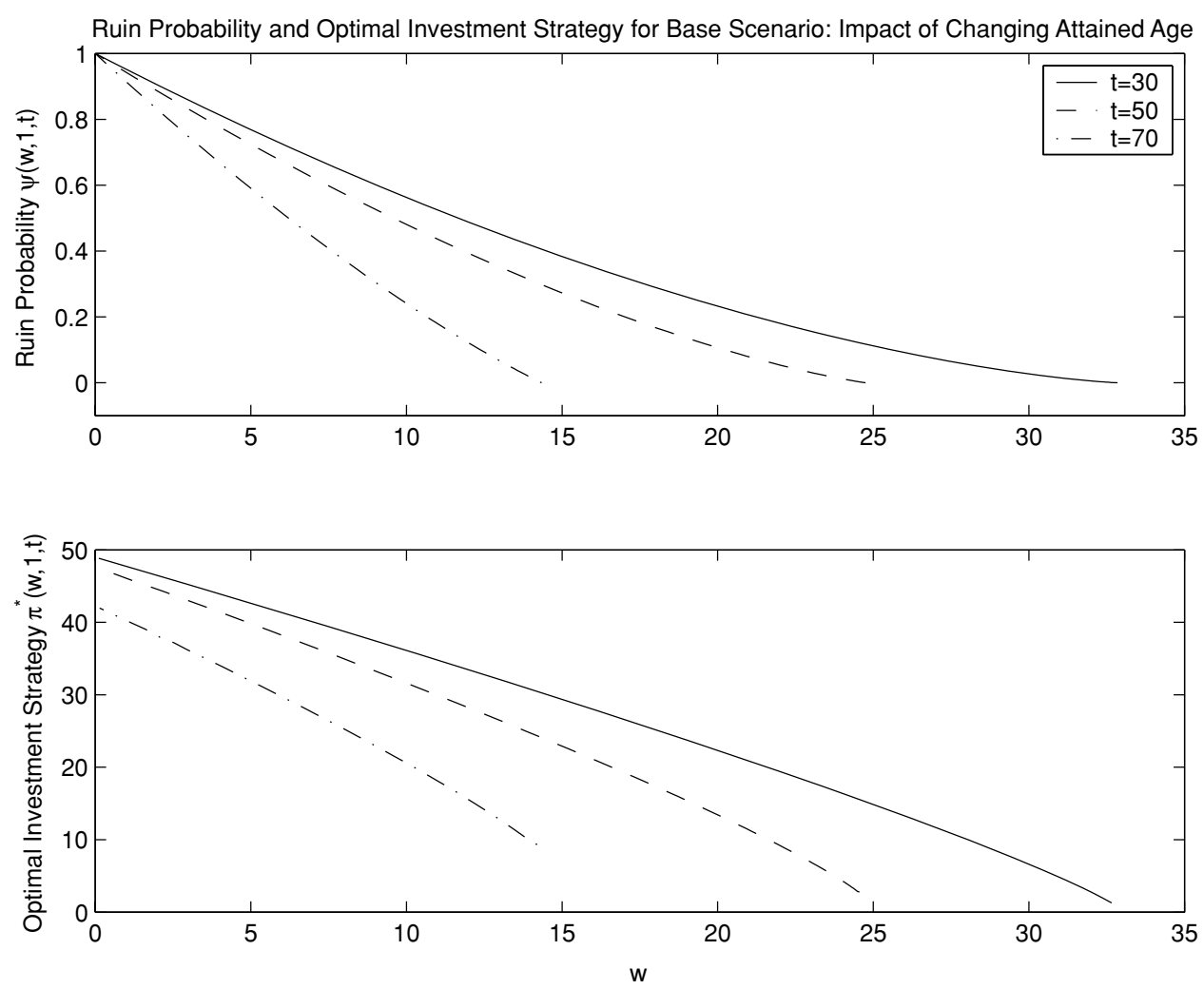

FIGURE 6.1. Ruin probabilities and optimal investment strategies as we vary the attained age $t$.

investor with wealth $w \in(0, \bar{a}(t))$ is more likely to ruin than an older investor with the same wealth. In addition, the younger individual will invest more in the risky asset than an older individual with the same wealth. This result is consistent with our financial intuition. Note that for some values of wealth, because we did not constrain $\pi^{*}$ in our problem formulation and perhaps because of the all-or-nothing nature of the investor's objective, the investment in the risky asset exceeds current wealth.

EXAMPLE 6.2. Impact of Stock Volatility: We next examine the impact of changing the volatility $\sigma$ of the stock return. Specifically, we consider $\sigma=0.1,0.2$, and 0.5 . We observe (not shown here) that for fixed wealth, the ruin probability increases and the optimal investment in the risky asset decreases with $\sigma$. This is consistent with our financial intuition.

EXAMPLE 6.3. Impact of Individual-Specific Mortality (Gompertz): We examine the impact of individual-specific mortality on the ruin probability and optimal investment strategy. We use the Gompertz assumption described above as the pricing mortality $\lambda^{O}(t)$, and we define the individual-specific mortality by $\lambda^{S}(t)=\lambda^{O}(t)+\eta$ for $\eta=-0.005,0$, and 0.005 . (For this example, we consider a 65 -year-old investor in order to avoid negative force of mortality.) We observe (not shown here) that individual-specific mortality has little impact on the probability of lifetime ruin. This occurs because the investor adjusts 
her investment strategy to compensate for the change in mortality; in effect, the change in strategy neutralizes the impact on the ruin probability of the change in subjective mortality. Indeed, an individual with lower mortality (and thus a longer investment horizon) invests more in the risky asset, which is consistent with Example 6.1.

Huang, Milevsky, and Wang (2004) examined lifetime ruin probability for an individual who invests in the risky asset only and who purchases no life annuities. They show that the probability of lifetime ruin for a 65 -year-old with initial wealth $\$ 20$ who consumes $c=1$ per year is approximately 0.57 . They also show that in order to sustain annual consumption of $c=1$ with a ruin probability of 0.05 , a 70 -year-old requires initial wealth of $\$ 27$. In our model, a 65 -year-old with only $\$ 17.05$ can purchase a life annuity to provide the desired consumption $c=1$ with zero probability of ruin. Moreover, a 65-year-old individual needs only $\$ 15.67$ to sustain consumption of $c=1$ with ruin probability 0.05 . Thus we see that, with dynamic portfolio management and life annuities, one can sustain the desired level of consumption with the same (or lower) ruin probability with lower wealth. (We remark that the parameter values in Huang, Milevsky, and Wang [2004] differ slightly from ours, but this does not change the qualitative comparison of the results.)

EXAMPLE 6.4. Impact of Individual-Specific Mortality (Constant Hazard Rate): We repeat the analysis of Example 6.3, but with constant hazard rate instead of the Gompertz hazard rate. We use pricing mortality $\lambda^{O}=0.04$ and consider an individual whose specific mortality is given by $\lambda^{S}=\lambda^{O}+\eta$ for $\eta=-0.015,0$, and 0.015 . We see in Figure 6.2 that the effect on the investment strategy is pronounced. In particular, for $\lambda^{S}=0.055$ and
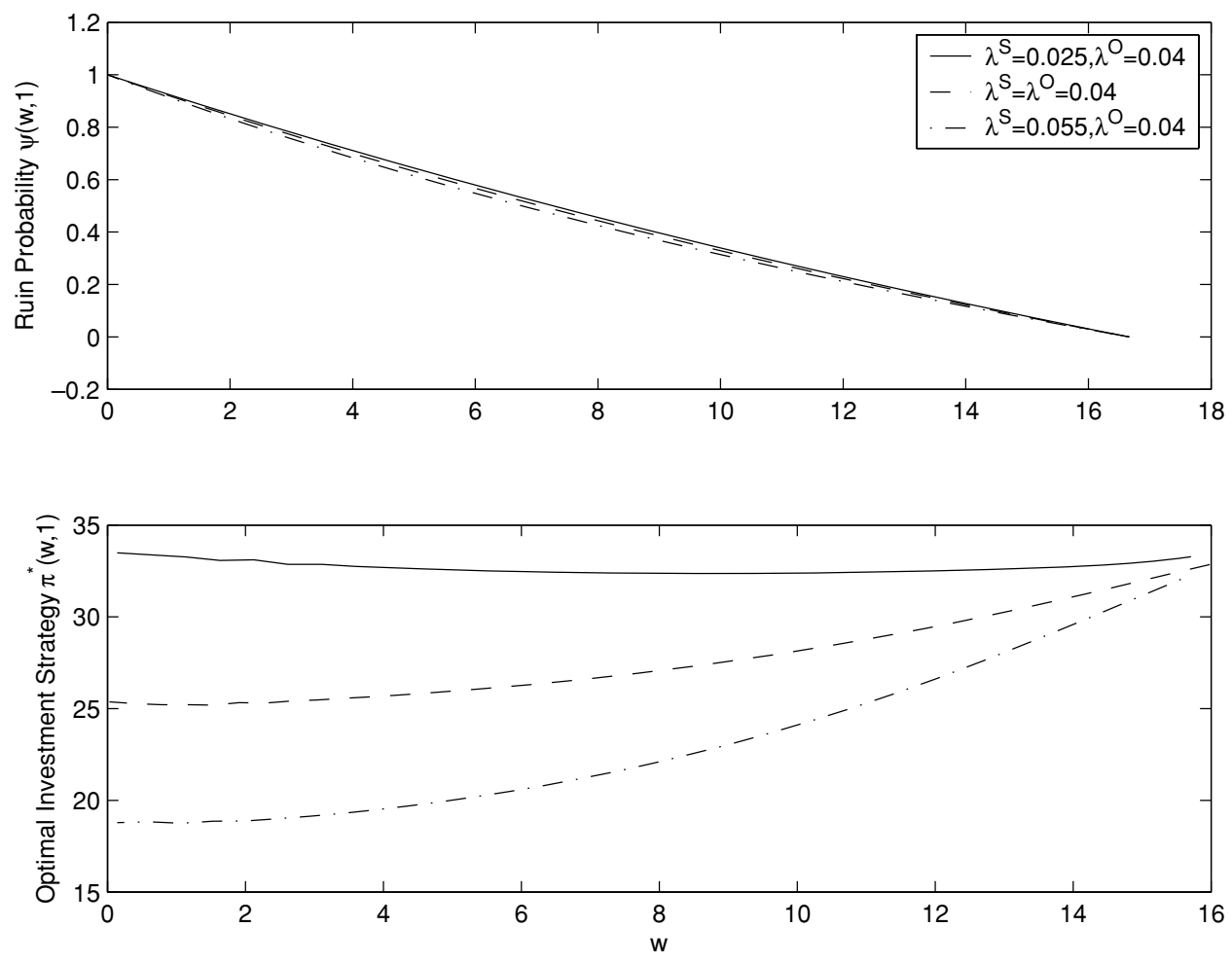

FIGURE 6.2. Constant hazard rate: Impact of individual-specific mortality. 

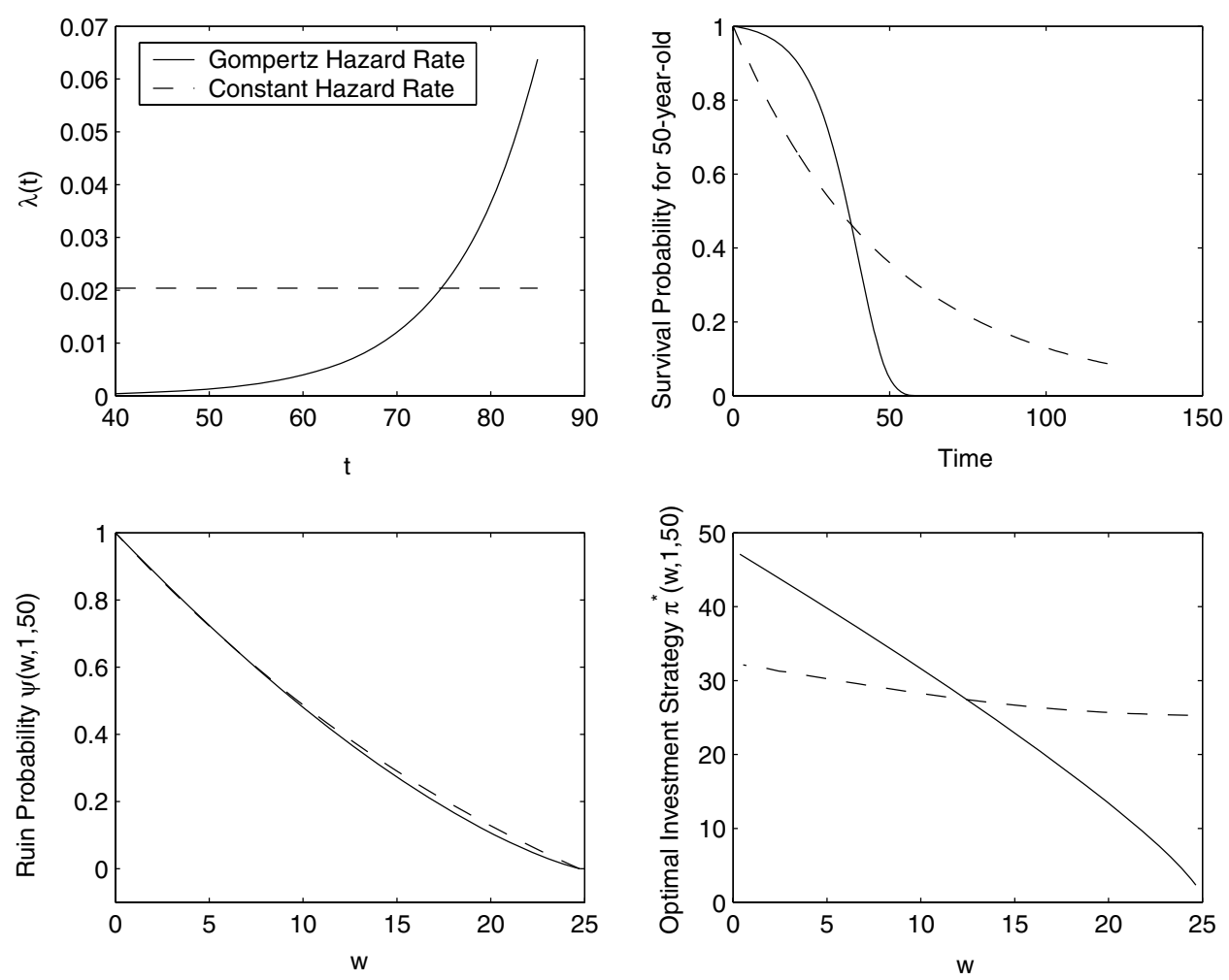

FIGURE 6.3. Both mortality assumptions above yield the same annuity price, but the shape of the hazard rate has significant impact on the optimal investment strategy.

$\lambda^{S}=0.04$, the optimal investment in the risky asset increases with wealth. For $\lambda^{S}=$ 0.025, it decreases with wealth. In Example 6.3, under Gompertz mortality, the optimal investment in the risky asset decreased with wealth regardless of $\lambda^{S}$.

EXAMPLE 6.5. Impact of Pricing Mortality: In Figure 6.3, we examine the impact of changing the objective (pricing) mortality assumption for a 50 -year-old whose specific mortality $\lambda^{S}$ equals the pricing mortality $\lambda^{O}$. More specifically, we examine the ruin probability and optimal strategy under two different mortality assumptions that yield the same price for a life annuity. For our base scenario, we assume Gompertz mortality with the parameters given above. Under this assumption, the price of the annuity is $\bar{a}(50)=24.75$. We contrast the ruin probability and optimal strategy under Gompertz mortality with the results under constant hazard rate with $\lambda^{S}=\lambda^{O}=0.0204$ (so that $\bar{a}(50)=24.75$ ). The first two graphs in Figure 6.3 show the hazard rates and corresponding survival probabilities. The fourth graph shows that the change in the mortality assumption has a dramatic impact on the optimal investment strategy. Thus, although both assumptions yield the same annuity price, the shape of the hazard rate has a significant effect on the optimal strategy. Under Gompertz mortality, the individual invests more in the risky asset at lower wealth levels because of the higher survival probability in the early years. As in the previous experiment, there is little change in the probability of ruin, as can be seen in the third graph of Figure 6.3. 


\section{CONCLUSION AND FUTURE RESEARCH}

In this paper, we derived the optimal investment and annuitization strategy for a retiree whose objective is to minimize the probability of lifetime ruin, namely the probability that a fixed consumption strategy will lead to zero wealth while the individual is still alive. We obtained a variety of interesting results. First, given the all-or-nothing objective, we found that the ruin-minimizing annuitization strategies are of the bang-bang, as opposed to gradual, type. In several of the numerical examples, we saw that the ruin probability and optimal strategies respond in an intuitive and predictable way to changes in the model parameters. However, the impact of the mortality assumption, and in particular, the shape of the hazard rate function, can be significant. Under some mortality assumptions, the optimal investment in the risky asset increases with wealth, while under other assumptions, it decreases.

For constant hazard rate, we explicitly showed the advantage of including annuities in the market from the standpoint of reducing the probability of lifetime ruin. When the hazard rate is more general, such as Gompertz, one can demonstrate that a similar advantage holds. See Moore and Young (2006) for the method to solve the ruin minimization problem when life annuities are not available in the market.

Finally, we note that we considered an unconstrained optimization problem; we did not restrict the investment in the risky asset to be less than or equal to current wealth, for example. Because of this and because of the binary nature of the investor's objective, in several examples, the optimal strategy was a heavily leveraged position in the risky asset. We plan to address this by considering the constrained problem in future work.

\section{REFERENCES}

Bowers, N. L., H. U. Gerber, J. C. Hickman, D. A. Jones, and C. J. Nesbitt (1997): Actuarial Mathematics, second edition. IL: Schaumburg, Society of Actuaries.

Brown, J. R. (2001): Private Pensions, Mortality Risk, and the Decision to Annuitize, J. Public Econ. 82(1), 29-62.

Browne, S. (1995): Optimal Investment Policies for a Firm with a Random Risk Process: Exponential Utility and Minimizing the Probability of Ruin, Math. Oper. Res. 20(4), 937-958.

BRowne, S. (1999a): Beating a Moving Target: Optimal Portfolio Strategies for Outperforming a Stochastic Benchmark, Finance Stoch. 3, 275-294.

Browne, S. (1999b): The Risk and Rewards of Minimizing Shortfall Probability, J. Portfolio Manag. 25(4), 76-85.

Browne, S. (1999c): Reaching Goals by a Deadline: Digital Options and Continuous-Time Active Portfolio Management, Adv. Appl. Probab. 31, 551-577.

Brugiavini, A. (1993), Uncertainty Resolution and the Timing of Annuity Purchases, J. Public Econ. 50, 31-62.

Copeland, C. (2002), An Analysis of the Retirement and Pension Plan Coverage Topical Module of SIPP, Issue Brief of the Employee Benefit Research Institute, www.ebri.org, May 2002.

Cummins, H. J. (2004): Bill Rewards Buyers of Life Annuities; Plan Would Give Retirees Half of the Income Tax-Free, Star Tribune, Minneapolis, Minnesota, July 29, 2004.

Davidoff, T., J. Brown, and P. Diamond (2003): Annuities and Individual Welfare, M.I.T. Department of Economics Working Paper Series, Working Paper 03-15.

Davis, M. H. A., and A. R. Norman (1990): Portfolio Selection with Transaction Costs, Math. Oper. Res. 15, 676-713. 
Dixit, A. K., and R. S. PINDYCK (1994): Investment under Uncertainty. Princeton, NJ: Princeton University Press.

Duffie, D., W. Fleming, H. M. Soner, and T. Zariphopoulou (1997): Hedging in Incomplete Markets with HARA Utility, J. Econ. Dyn. Contr. 21, 753-782.

Feldstein, M., and E. Ranguelova (2001): Individual Risk in an Investment-Based Social Security System, Am. Econ. Rev. 91(4), 1116-1125.

Friedman, A., and W. SHEN (2002): A Variational Inequality Approach to Financial Valuation of Retirement Benefits Based on Salary, Finance Stoch. 6(3), 273-302.

Gerber, H. U. (1979): An Introduction to Mathematical Risk Theory, S.S. Heubner Foundation Monograph Series, 8, University of Pennsylvania, Wharton School, Philadelphia.

HARrison, J. M., and M. I. TAKSAR (1983): Instantaneous Control of Brownian Motion, Math. Oper. Res. 8(3), 439-453.

Huang, H., M. A. Milevsky, and J. Wang (2004): Ruined Moments in Your Life: How Good Are the Approximations? Insurance: Math. Econ. 34(3), 421-447.

Kapur, S., and M. OrsZag (1999): A Portfolio Approach to Investment and Annuitization during Retirement, Working Paper, Birkbeck College, University of London.

Karatzas, I., and S. Shreve (1998): Methods of Mathematical Finance. New York: SpringerVerlag.

Koo, H. K. (1998): Consumption and Portfolio Selection with Labor Income: A Continuous Time Approach, Math. Fin. 8, 49-65.

Milevsky, M. A., and V. R. Young (2003): Annuitization and Asset Allocation, Working Paper, Schulich School of Business, York University.

Milevsky, M. A., and C. Robinson (2000): Self-Annuitization and Ruin in Retirement, N. Am. Actuarial J. 4(4), 112-129.

Moore, K. S., and V. R. Young (2006): Optimal and Simple, Nearly Optimal Rules for Minimizing the Probability of Ruin in Retirement, Submitted for publication.

Neuberger, A. (2002): Optimal Annuitization Strategies, Working Paper, London Business School.

ØKSENDAL, B. (1998): Stochastic Differential Equations: An Introduction with Applications, 5th edition. Berlin: Springer-Verlag.

PARIKh, A. N. (2003): The Evolving U.S. Retirement System, The Actuary, March: 2-6.

Poterba, J. M. (1997): The History of Annuities in the United States, NBER Working Paper 6004.

RichARD, S. (1975): Optimal Consumption, Portfolio and Life Insurance Rules for an Uncertain Lived Individual in a Continuous Time Model, J. Financ. Econ. 2, 187-203.

Roy, A. D. (1952): Safety First and the Holding of Assets, Econometrica 20, 431-439.

SHreve, S. E., and H. M. Soner (1994): Optimal Investment and Consumption with Transaction Costs, Ann. Appl. Probab. 4(3), 206-236.

SOCIETY OF ACTUARIES (2004): Risks of Retirement-Key Findings and Issues, www.soa.org.

VanDerhei, J., and C. Copeland (2003): Can America Afford Tomorrow's Retirees: Results from the EBRI-ERF Retirement Security Projection Model, Issue Brief of the Employee Benefit Research Institute, www.ebri.org, November 2003.

Wilmott, P., J. Dewynne, and S. Howison (2000): Option Pricing: Mathematical Models and Computation. Oxford: Oxford Financial Press.

YAARI, M. E. (1965): Uncertain Lifetime, Life Insurance and the Theory of the Consumer, Rev. Econ. Stud. 32, 137-150. 
YounG, V. R. (2004): Optimal Investment Strategy to Minimize the Probability of Lifetime Ruin, N. Am. Actuarial J. 8(4), 106-126.

Zariphopoulou, T. (1992): Investment/Consumption Models with Transaction Costs and Markov-Chain Parameters, SIAM J. Control Optim. 30: 613-636.

ZARIPHOpoulou, T. (1999): Transaction Costs in Portfolio Management and Derivative Pricing, in Introduction to Mathematical Finance, D. C. Heath and G. Swindle, eds. Providence, RI: American Mathematical Society. Proceedings of Symposia in Applied Mathematics, 57, 101163.

Zariphopoulou, T. (2001): Stochastic Control Methods in Asset Pricing, in Handbook of Stochastic Analysis and Applications, D. Kannan and V. Lakshmikantham, eds. New York: Marcel Dekker. 